\title{
Skills versus Luck: Bolivia and its recent Bonanza
}

\author{
Rómulo A. Chumacero* ${ }^{*}$
}

\section{${ }^{*}$ Correspondence:}

rchumace@econ.uchile.cl Department of Economics of the University of Chile, Santiago, Chile

\begin{abstract}
This paper uses different approaches to determine the contribution of internal policies and external factors on the good performance of the Bolivian economy in the recent past. It is demonstrated that the extremely favorable external conditions are mainly responsible for its bonanza, and that the domestic policies have, probably, caused more harm, than good. The extent of the harm ranges from $2 \%$ to up to $6.1 \%$ of GDP per capita.
\end{abstract}

Keywords: Bolivia, Synthetic control, Panel data, DSGE

JEL Classification: C32, C33, C53, E65

\section{Introduction}

Governments have the tendency to attribute good outcomes to their policies (skills) and bad ones to negative external shocks outside of their control (luck). That is certainly the case in Bolivia.

As in many other dimensions, the economic debate regarding the sources of the economic performance during the (continuing) tenure of President Evo Morales, is polarized. Opponents consider that most (if not all) of the good economic indicators are due to extraordinarily favorable external conditions. ${ }^{1}$ Acolytes consider that a major role has to be attributed to the heterodox policies that the government has implemented, and compare favorably recent economic indicators, against the ones of, what they tend to call, the "neoliberal past" (Arce 2016).

Economists have long understood that one of the most prevalent and pernicious logical fallacies is to attribute a causal effect to a correlation. ${ }^{2}$ Thus, a rigorous effort to ascertain how important were skills (or lack thereof) and luck, requires more than informal comparisons, declarations, and charts. ${ }^{3}$

Answering this question is not easy, as an obvious counterfactual is not readily available. That is, ideally, we would like to know how would Bolivia have fared if faced with the same external conditions, but with different internal policies than the ones pursued by

\footnotetext{
${ }^{1}$ Morales (2014) edits a volume that presents several studies quantifying the magnitude of resources that Bolivia received, thanks to the commodities prices boom.

2 The Latin phrase "post hoc, ergo propter hoc" (after this, therefore, because of this) is a logical fallacy that states that because two events occurred in succession, the former event must have caused the latter event.

3 To my knowledge, there are no systematic studies that have tackled this question for the case of Bolivia.
} 
President Morales. In experimental terms, we would like to quantify what were the effects of receiving the "Evo Morales treatment," when no natural control group is available.

This paper attempts to do so, using three methodologies. For completeness, each one is described, justified, and implemented. Presenting more than one approach helps to narrow down the possible answers, highlights their strengths and weaknesses, and provides robustness checks.

The rest of the paper is organized as follows: Sect. 2 describes and implements a methodology known as the synthetic control method. Section 3 uses a panel data model. Section 4 uses a simple dynamic stochastic general equilibrium model (DSGE). Finally, Sect. 5 concludes.

\section{Synthetic control approach}

Establishing a counterfactual to evaluate the relative merits of the policies implemented in Bolivia since 2006 is not simple. Ideally, we would like to have Bolivia face the same external conditions, but carry out different policies. In that case, the differences in outcomes between the treatment unit (policies implemented during Morales's Presidency) and the control unit could be, in principle, attributed to the policies.

Abadie and Gardeazabal (2003) and Abadie et al. (2010) proposed a method that creates a statistical synthetic control that can be used as a counterfactual on a given treatment. Closely related to our approach, Grier and Maynard (2016) applied this method to assess the economic consequences of Venezuela's Hugo Chavez.

This section describes the methodology, discusses practical issues of its implementation, and presents its results, when applied to Bolivia.

\subsection{The method}

As the ideal experiment, in which the systematic difference among two groups is clearly defined, is generally not available in social sciences, causal inference about the effects of events requires the development of different techniques. When there are several control and treatment units, facing similar environments, with or without common trends, a number of econometric techniques can be used to measure average treatment effects on the treated. ${ }^{4}$

In the present circumstances, there is only one treatment unit (Bolivia, under the Presidency of Evo Morales) and no natural control units that can be used as counterfactuals. As Grier and Maynard (2016) for the case of Venezuela, we want to evaluate how different variables would have evolved, without Evo Morales and his policies.

Synthetic control methods were specifically developed to address issues like this one. Intuitively, we want to construct a synthetic Bolivia that is a weighted average of other countries, and that closely resembles conditions in Bolivia prior to the "treatment," which, in this case, is Evo Morales taking office in 2006. If the synthetic control captures other influences common to Bolivia, we use this synthetic Bolivia to compare the effect of Evo Morales on different outcomes. ${ }^{5}$

\footnotetext{
${ }^{4}$ Textbook treatments of alternatives are discussed in Angrist and Pischke (2009), Imbens and Rubin (2015), Lee (2016), and Pan and Bai (2015).

5 As pointed out by one of the referees, this method can be used to assess if the "Evo Morales treatment" is relevant, but not to evaluate the relative importance of the external and internal factors.
} 
Following Abadie and Gardeazabal (2003), let $X_{1}$ be a $k \times 1$ vector of pre-treatment observations of economic and social indicators of the treatment unit (Bolivia). ${ }^{6}$ Let $X_{0}$ be a $k \times N$ matrix which contains $k$ observations of the same variables as $X_{1}$, but for the $N$ countries considered to build the synthetic control. Let $V$ be a $k \times k$ diagonal weighting matrix that reflects the relative importance of the $k$ indicators considered in $X_{0}$ and $X_{1}$. Given $V$, the objective is to find the $N \times 1$ vector of weights $W(V)$ that minimizes the objective function:

$$
W(V)=\underset{W}{\arg \min }\left(X_{1}-X_{0} W\right)^{\prime} V\left(X_{1}-X_{0} W\right),
$$

subject to the constraints that each element of $W$ satisfies that $w_{i} \geq 0(i=1,2, \ldots, N)$ and $W^{\prime} \iota=1$, where $\iota$ is an $N$-vector of ones.

As in Abadie and Gardeazabal (2003), let $Z_{1}$ be a $j \times 1$ vector of pre-treatment observations of the variable that we are interested in comparing. Let $Z_{0}$ be the $j \times N$ matrix which contains $j$ observations of the same variable of interest, for the $N$ potential controls. Define $\widehat{V}$ as the nonnegative diagonal weighting matrix that solves:

$$
\widehat{V}=\underset{V}{\arg \min }\left(Z_{1}-Z_{0} W(V)\right)^{\prime}\left(Z_{1}-Z_{0} W(V)\right),
$$

so that $\widehat{W}=W(\widehat{V})$ is the vector of weights that minimizes (1), given the matrix $V$ that minimizes (2).

Several observations are in order. First, given $V$, the minimization of (1) is simple as it corresponds to a quadratic programming problem with linear constraints that has an analytical solution. Second, although the simultaneous optimization of (1) and (2) could be conducted, the objective function is no longer quadratic, and numerical methods would be required. Third, a simpler way to proceed is to apply a sequential approach, in which we first consider a wide variety of candidates of $V$, obtain the value of $W$ that minimizes (1) for each candidate, and evaluate which of those candidates minimizes (2). This procedure is numerically more stable than the simultaneous approach, as long as the candidates of $V$ are dense enough. This is the approach that we pursue here. ${ }^{7}$

Once the optimal weights, $\widehat{W}$, are obtained, we can evaluate if, before the treatment, the synthetic control thus generated resembles the economy that we are trying to replicate. For that, we can consider the difference between $X_{1}$ and $\widehat{X}_{1}$, and $Z_{1}$ and $\widehat{Z}_{1}$, where:

$$
\widehat{X}_{1}=X_{0} \widehat{W}, \quad \widehat{Z}_{1}=Z_{0} \widehat{W} .
$$

That is, we evaluate if the weighted average of the control group (other countries) approximates well the pre-treatment characteristics of Bolivia $\left(X_{1}\right)$, and the behavior of the pre-treatment variable of interest $\left(Z_{1}\right)$.

\footnotetext{
${ }^{6}$ The choice of $X_{1}$ should consider characteristics that could be interpreted as fundamentals behind the output variable, or a comprehensive description of the pre-treatment Bolivia.

7 We consider one hundred thousand candidates for $V$, generated using pseudo-random numbers. $V$ is always normalized such that its trace is one.
} 
Table 1 Optimal weights for synthetic control: GPD per capita

\begin{tabular}{lc}
\hline Country & Weight \\
\hline Cote d'Ivoire & 0.0620 \\
Kyrgyz Republic & 0.1557 \\
Niger & 0.0424 \\
Peru & 0.5192 \\
Togo & 0.1096 \\
UK & 0.0397 \\
Uruguay & 0.0631 \\
Zimbabwe & 0.0083 \\
\hline
\end{tabular}

To evaluate the effect of the treatment, we can use the vector of weights $\widehat{W}$ obtained using pre-treatment information, to compare the post-treatment outcomes of the variable of interest. That is, let $Y_{1}$ be a $l \times 1$ vector of post-treatment observations of the variable that we are interested in comparing. Let $Y_{0}$ be the $l \times N$ matrix which contains $l$ observations of the same variable of interest for the $N$ potential controls. The goal of approximating the behavior that the outcome variable of interest would have had in the absence of Evo Morales, can be obtained by considering the counterfactual generated by our synthetic Bolivia. Thus, the effect of Evo Morales on the variable of interest can be defined as:

$$
\Delta=Y_{1}-\widehat{Y}_{1}=Y_{1}-Y_{0} \widehat{W} .
$$

To address the issue of the significance of the results, and if the differences can be attributed to the treatment, Abadie et al. (2010) suggest performing a "placebo study." It consists on applying the synthetic control method to all the countries in the control group (that, of course, did not have Evo Morales as their president). If the placebos generate gaps similar to the ones of (3), we would conclude that the treatment (Evo Morales) did not have a significant effect on the variable of interest. On the other hand, if the treated unit displays a different behavior than the placebos, we would conclude that there is significant evidence of the effect of the treatment.

\subsection{Results}

Here we present the results of applying the methodology described above to evaluate the effects of the Evo Morales Presidency on (the natural log of) GDP per capita at purchasing power parity (PPP). ${ }^{8}$ We consider the years $1992-2005$ for constructing $Z_{1}$ in the pre-treatment period, and the period 2006-2016 as the treatment period.

Table 1 presents the results of applying the methodology described above to obtain the optimal weights $\widehat{W}$. Eight countries have positive weights to compose the synthetic control (Cote d'Ivoire, Kyrgyz Republic, Niger, Peru, Togo, UK, Uruguay, and Zimbabwe).

\footnotetext{
${ }^{8}$ Appendix 1 describes the datasets used. Appendix 2 presents the results of the synthetic control approach for the Gini coefficient, primary school dropout rate, infant mortality, and life expectancy.
} 
Table 2 Pre-treatment characteristics

\begin{tabular}{llll}
\hline & Real & Synthetic & Average \\
\hline Access to electricity (1990-2005) & 65.49 & 66.78 & 80.67 \\
Energy use (1990-2005) & 494.83 & 625.53 & 2280.55 \\
Investment rate (1990-2005) & 16.03 & 17.67 & 22.57 \\
Health expenditures (1990-2005) & 5.32 & 5.31 & 6.23 \\
Human capital (1990-2005) & 2.40 & 2.35 & 2.47 \\
Improved water (1990-2005) & 76.05 & 75.70 & 86.59 \\
Inflation (2005) & 5.39 & 5.71 & 72.20 \\
Net barter terms of trade (1990-2005) & 98.26 & 96.15 & 78.58 \\
Openness (1990-2005) & 50.27 & 50.39 & 34.68 \\
Prevalence of anemia (1990-2005) & 54.27 & 54.07 & 15.75 \\
Share of gov. expenditures (1990-2005) & 14.28 & 12.63 & 0.65 \\
Total factor productivity (1990-2005) & 0.37 & 0.42 & 84 \\
Countries & 1 & 8 & 1.11 \\
RMSPE & 0 & 0.10 & \\
\hline
\end{tabular}

All variables are averaged for the period in parenthesis. Real is the average for Bolivia $\left(X_{1}\right)$. Synthetic is the value for synthetic Bolivia $\left(\widehat{X}_{1}\right)$. Average is the simple average for all the countries considered to build the synthetic control. Countries denote the number of countries considered. RMSPE denotes the root mean squared percentage error when compared to Bolivia. Further data description is in Appendix 1

Table 2 presents the list of pre-treatment characteristics that we seek to match. These characteristics take into account, not only, conventional factors considered as determinants of economic conditions, but also other social indicators that provide a broad characterization of the pre-treatment conditions faced by Bolivia. ${ }^{9}$ The table shows that Bolivia is considerably poorer than the simple average of the 84 countries for which the information is available, and that are used to obtain the synthetic control. It also shows that, with the possible exception of energy use, the synthetic control does a good job replicating Bolivia's pre-treatment characteristics. Suffice it to say that synthetic Bolivia has a RMSPE that is more than eleven times smaller than the average of all countries.

Figures 1 and 2 display the evolution of the level of GDP per capita (at PPP) for Bolivia, the average of the 84 countries considered as possible controls, and the synthetic control. As it happened with the pre-treatment characteristics, the average corresponds to more than two times the income of Bolivia, thus not being a suitable control. However, the synthetic control matches the behavior of Bolivia very closely up to the period of the treatment. After 2005, the synthetic control and actual Bolivia sharply diverge, especially up to 2014. In particular, if synthetic Bolivia were a valid counterfactual, the gap between the actual Bolivia and the synthetic control is, on average, of US\$ 270 (at PPP).

To evaluate the significance of the results we conduct the "placebo" test described in Abadie et al. (2010). ${ }^{10}$ To do so, we conduct the same synthetic control method to the

\footnotetext{
${ }^{9}$ One issue that is particularly relevant is to assess the importance of "luck," measured by improved terms of trade. As terms of trade shocks can be considered as exogenous, we could use them as another relevant characteristic for the synthetic control. Including net barter terms of trade in the 2006-2016 period as an additional $X$ variable does not significantly alter the results reported here.

10 This inferential tool is also known as the "falsification" or "refutability" test, intended to evaluate if the results obtained may be due to pure chance. See Abadie et al. (2010) for further references.
} 


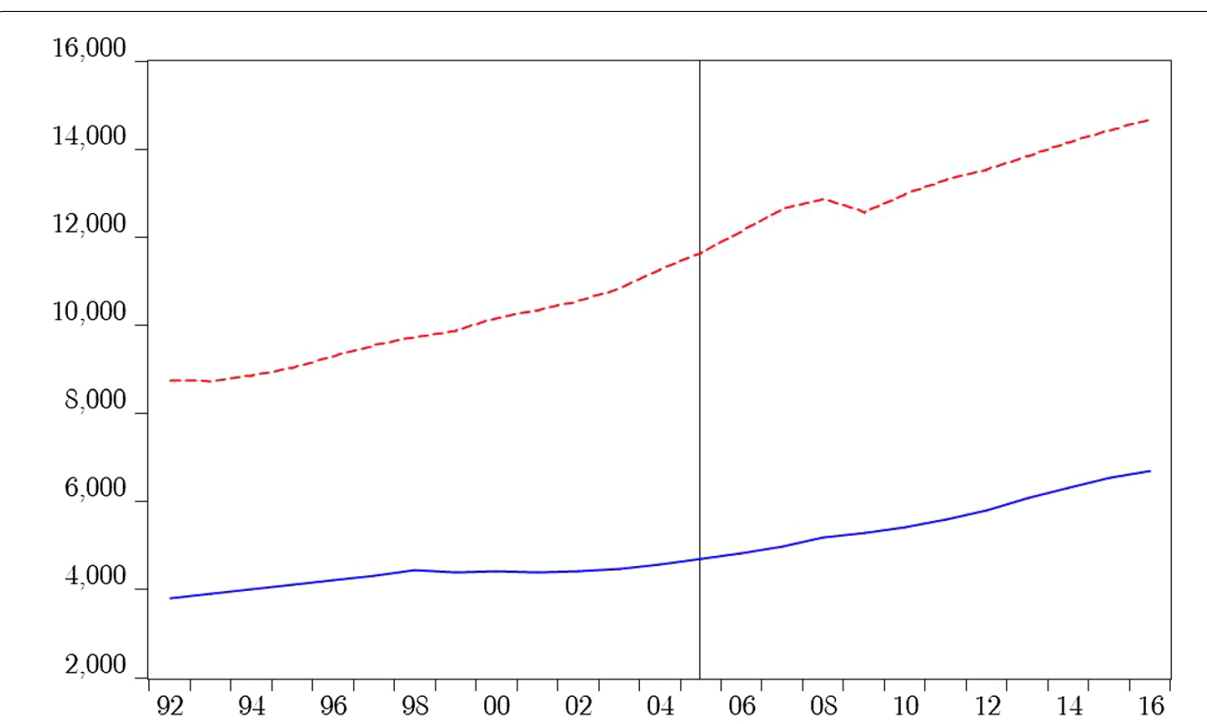

Fig. 1 GDP per capita (at PPP): possible controls. The solid line represents Bolivia. The dashed line represents the simple average of the 84 countries considered as possible controls. The vertical line corresponds to the year prior to the treatment (2005)

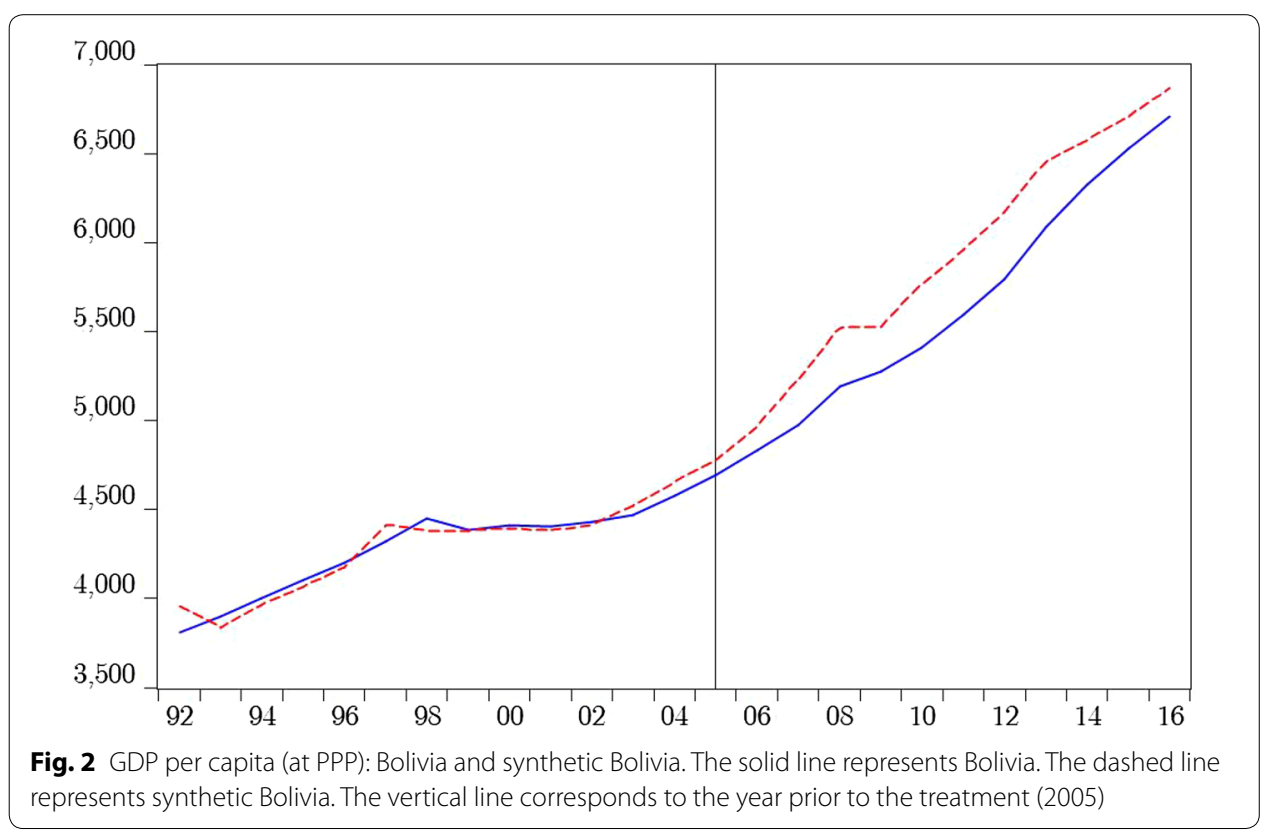

84 countries used as our control. ${ }^{11}$ As they did not have Evo Morales as their president since 2006, if the placebo gaps are similar to the one obtained for Bolivia, we would conclude that our results are not attributable to Morales and his policies. However, if the gap estimated for Bolivia is large compared to the gaps for the other countries, we would

\footnotetext{
$\overline{11}$ The placebo test requires to perform the optimization procedure described above for each country. For computational expediency, we consider one thousand randomly generated candidates for $V$.
} 


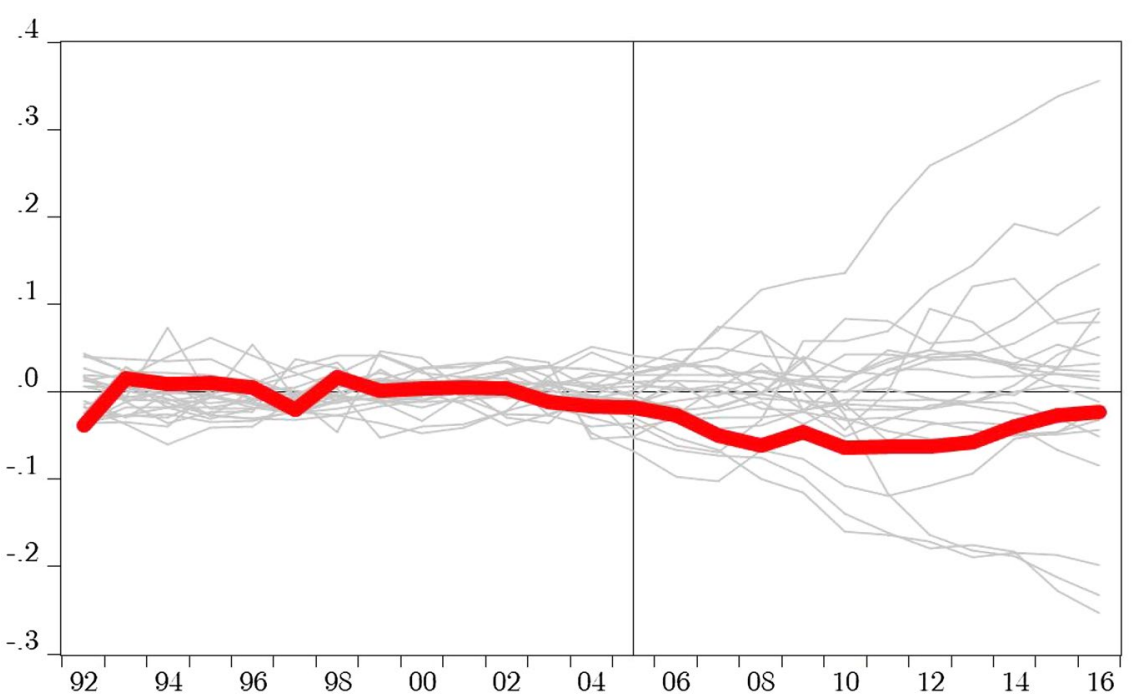

Fig. 3 Placebo test for (log of) GDP per capita (at PPP). The bold line represents the difference between the (log of) observed GDP per capita in Bolivia and the synthetic control. The gray lines represent placebo tests deviations for the other countries in the data set. The graph excludes countries with pre-treatment RMSE 2.2 times higher than Bolivia. The vertical line corresponds to the year prior to the treatment (2005)

conclude that the Morales Presidency had a significantly negative impact on GDP per capita.

Figure 3 presents the results of this exercise. Following Abadie et al. (2010), the placebo gaps depicted exclude the countries for which their RMSEs prior to the treatment are 2.2 times higher than Bolivia's. The reason for doing so is that we want to include only countries that have synthetic controls that can reproduce relatively well the pre-treatment behavior of (the log of) GDP per capita prior to the treatment. ${ }^{12}$ From this exercise we conclude that the differences are consistently negative between actual Bolivia and synthetic Bolivia, and are significant. On average, the gap between actual Bolivia and synthetic Bolivia is of $4.7 \%$ of GDP per capita, with a peak of up to $6.3 \%$ of GDP per capita between 2010 and 2012. ${ }^{13}$

Again, following Abadie et al. (2010), one final way to compare the Bolivia gap relative to the gaps in the placebo test, is to consider the ratios of the post-/pre-treatment RMSE for each country and their synthetic control. A large ratio indicates that the posttreatment period is significantly different than the pre-treatment period. Figure 4 shows that the post-treatment Bolivia is significantly different than the pre-treatment Bolivia when compared to its synthetic control. Indeed, the post-treatment RMSE is more than three times higher than the pre-treatment RMSE, pertaining to the right tail of the distribution.

\footnotetext{
${ }^{12}$ As in Abadie et al. (2010), we also considered excluding of the placebo test countries that present more than 4.5 times the RMSE of Bolivia, with similar resuls.

13 Even bigger effects, of up to 6\%, were found using GDP per capita (without the PPP conversion). Although the magnitude may also vary depending on the pre-treatment characteristics included, whenever they were matched, synthetic Bolivia performed systematically better than actual Bolivia during the "Evo Morales treatment".
} 


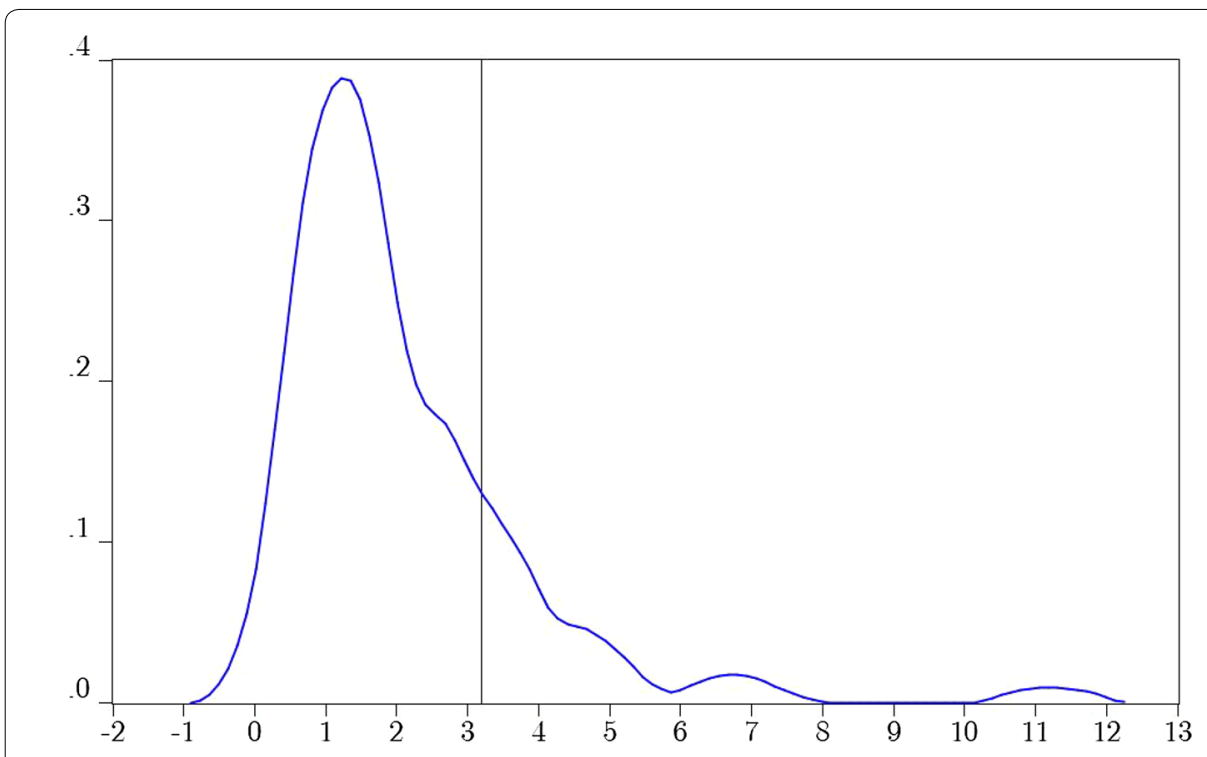

Fig. 4 Ratio of post- and pre-treatment RMSE. Estimation of the empirical density of post-/pre-treatment RMSE using the Epanechnikov kernel. The vertical line corresponds to the ratio of RMSE of Bolivia

Summarizing, we show that Bolivia underperformed when compared to its synthetic counterfactual, in terms of the behavior of GDP per capita. While the synthetic control replicates relatively well broad characteristics of Bolivia prior to the treatment, it performs markedly better than actual Bolivia since the year 2006. This exercise suggest that, on average, Bolivia may have lost $4.7 \%$ of GDP per capita because of the treatment (Evo Morales Presidency). Furthermore, as evidenced in Appendix 2, there is no evidence that the Morales Presidency achieved better results than its synthetic counterpart when considering outcomes such as inequality (measured by the Gini coefficient), school dropout rate, infant mortality rate, or life expectancy. Although not in the same magnitude, these results are similar in spirit, to those encountered by Grier and Maynard (2016) for Chavez's Venezuela.

\section{Panel data approach}

The previous section tackles the fact that there is no obvious control group with which to evaluate the effect of the Evo Morales Presidency. That is so, because the other countries differ from Bolivia, not only on who is their President, but also on their economic structure, external shocks they face, etc. The synthetic control approach deals with this problem by building an artificial control that, hopefully, resembles the actual Bolivia, prior to the treatment, and compares an outcome variable of the actual Bolivia, with the synthetic counterfactual, after the treatment on Bolivia.

Under certain conditions, cross-country panel data models could be used to evaluate this same question, without having to construct a synthetic control. ${ }^{14}$ This section

\footnotetext{
$\overline{{ }^{14} \text { For example, Easterly et al. (1993) evaluate the importance of internal versus external determinants of levels and }}$ growth rates of GDP.
} 
describes the methodology followed. If anything, this approach can be used to assess the robustness of the results obtained above.

\subsection{The method}

Lucas (1987) describes methodological aspects that should be considered to evaluate alternative policies. First, describe the environment in which the agents interact, their preferences, technologies, and constraints they face. Second, determine their optimal plans or policy functions of the control variables $(y)$. Then, alter the laws of motion of the state or forcing variables $(x)$. Finally, evaluate how the agents react to these alterations.

Under certain conditions, an econometric exercise can achieve the same goal. To do so, consider the conditional density as the empirical equivalent of the policy function, and the marginal density as the law of motion of the state variables. Recalling that the joint density can be written as the product of the conditional density and the marginal density, we have:

$$
f\left(y_{t}, x_{t}, \theta\right)=f\left(y_{t} \mid x_{t}, \theta_{1}\right) f\left(x_{t}, \theta_{2}\right),
$$

where $f\left(x_{t}, \theta_{2}\right)=\int_{-\infty}^{\infty} f\left(y_{t}, x_{t}, \theta\right) d y$ is the marginal density of $x$, and $\theta, \theta_{1}$, and $\theta_{2}$ are the vectors of parameters of the joint, conditional, and marginal densities, respectively.

Regression analysis usually focuses on statistical inference of some moments of the conditional density. To do so ignoring the marginal density requires for $\theta_{1}$ and $\theta_{2}$ to be "variation free". ${ }^{15}$ This condition is not sufficient for conducting counterfactual analysis. To do so, it is required for the conditional density (or its relevant moments) to be structurally invariant. That is, that the parameters of interest in the conditional density remain unchanged, in the presence of an unstable marginal density. ${ }^{16}$ If those conditions are met, evaluating counterfactual scenarios would imply comparing the forecasts of the variable of interest under alternative trajectories of the state variables.

We are interested in evaluating how external shocks and internal conditions (or policies) affected the trajectory of the variable of interest: (log of) GDP per capita. Considering solely information of Bolivia would be advisable if enough quality data for approximating internal conditions were available. Unfortunately, this is not the case.

An alternative approach, followed here, is to consider a panel data structure. Under certain homogeneity conditions, this structure would lead not only to consistent, but also more efficient estimates than the ones obtained with time series models for one country. Of course, panel data models tend to assume that the only source of heterogeneity (difference) among units is a fixed effect, which can be a strong assumption.

Formally, we estimate the following simple dynamic specification:

$$
y_{i, t}=\alpha_{i}+\sum_{j=1}^{J} \delta_{j} y_{i, t-j}+\beta x_{i, t}+\gamma p_{i, t}+\phi x_{i, t} p_{i, t}+\theta t+u_{i, t}
$$

where $y_{i, t}$ is the (log of) GDP per capita (at PPP) of country $i$ in year $t, x_{i, t}$ is a proxy for external conditions, $p$ is a proxy for internal policies, $t$ is a time trend, and $J$ is the number of lags necessary to make $u_{i, t}$ a white noise process for each country.

${ }^{15}$ In this case, we say that $x$ is "weakly exogenous" for $\theta_{1}$. See Hendry (1995) for details.

16 In this case, we say that $x$ is "super exogenous" for $\theta_{1}$. See Hendry (1995) for details. 
A few comments regarding (4) are in order. First, $\alpha_{i}$ summarizes the heterogeneity considered as a fixed effect. Second, the lags of the dependent variable are intended to capture the persistence of the series. Third, the series of interest is considered to be trend stationary. ${ }^{17}$ Fourth, this specification allows for differences in short, and long-run impacts of changes of the forcing variables. To conduct valid inference, this specification requires that $x$ and $p$ be weakly exogenous to the parameters of interest. Furthermore, to conduct counterfactual evaluations, these variables must be super exogenous to the parameters of interest. Finally, in the spirit of Chang et al. (2009), we consider the interaction between internal and external factors, as described by the parameter $\phi .{ }^{18}$ The main idea is that good policies may act as enhancers (complements) of good external conditions. ${ }^{19}$

The choice of a simple structure is deliberate, as there are not many observations in the panel structure for Bolivia. If the model were misspecified (as all are), we would want to avoid systematic and persistent errors for Bolivia. Thus, after the estimation of the parameters using a panel structure, we conduct exogeneity and specification tests for the residuals of Bolivia.

Next, we describe the choice of variables and results of implementing this strategy.

\subsection{Results}

A natural proxy for external conditions is the evolution of (the log of) the terms of trade, which we use. Internal conditions are trickier to proxy, as they should reflect policy decisions, and their distortionary effects on the decisions of private agents. Furthermore, the variable(s) used to characterize this feature should have a time span useful for estimation and be comparable between countries. ${ }^{20}$

Chumacero and Fuentes (2006) use the ratio of government expenditures to GDP as a proxy of these distortions. However, this is not a good proxy for government intervention for Bolivia in the recent past, as the distinction between government expenditures and investment has become increasingly blurred. Instead, we consider summary indexes that evaluate overall, and other types of freedom, constructed by the Heritage Foundation. As Fig. 5 makes clear, irrespective of the index considered, Bolivians have experienced their freedoms curtailed, and thus, distortions increased since Evo Morales became president. ${ }^{21}$

The choice of the variable used to proxy internal conditions was done following the general-to-specific approach suggested by Hendry (1995). That is, we consider the candidates presented in Fig. 5, estimate Eq. (4), perform specification tests for each candidate, and eliminate non-significant variables. Although these variables display similar patterns (in terms of direction), the Labor Market Freedom Index best captures the interaction

\footnotetext{
${ }^{17}$ As is well known, the parameter associated with the trend component is super consistent. Thus, even if the variable were difference stationary, the process still has a valid representation, if cointegration is present.

18 A dynamic structure that includes lags of $x$ and $p$ can be considered. However, information (particularly of proxies of $p$ ) is not abundant for Bolivia. Thus, we privilege parsimony and conduct specification tests.

19 As the quote attributed to the Roman philosopher Seneca states, "luck is what happens when preparation meets opportunity" .

20 See Appendix 1 for the list of variables considered and their sources.

${ }^{21}$ In fact, the 2019 report of the Heritage Foundation ranks Bolivia in place 173 out of 180 in terms of overall freedom, characterizing it is "repressed" . Other countries in this category are Cuba (178), Venezuela (179), and North Korea (180).
} 


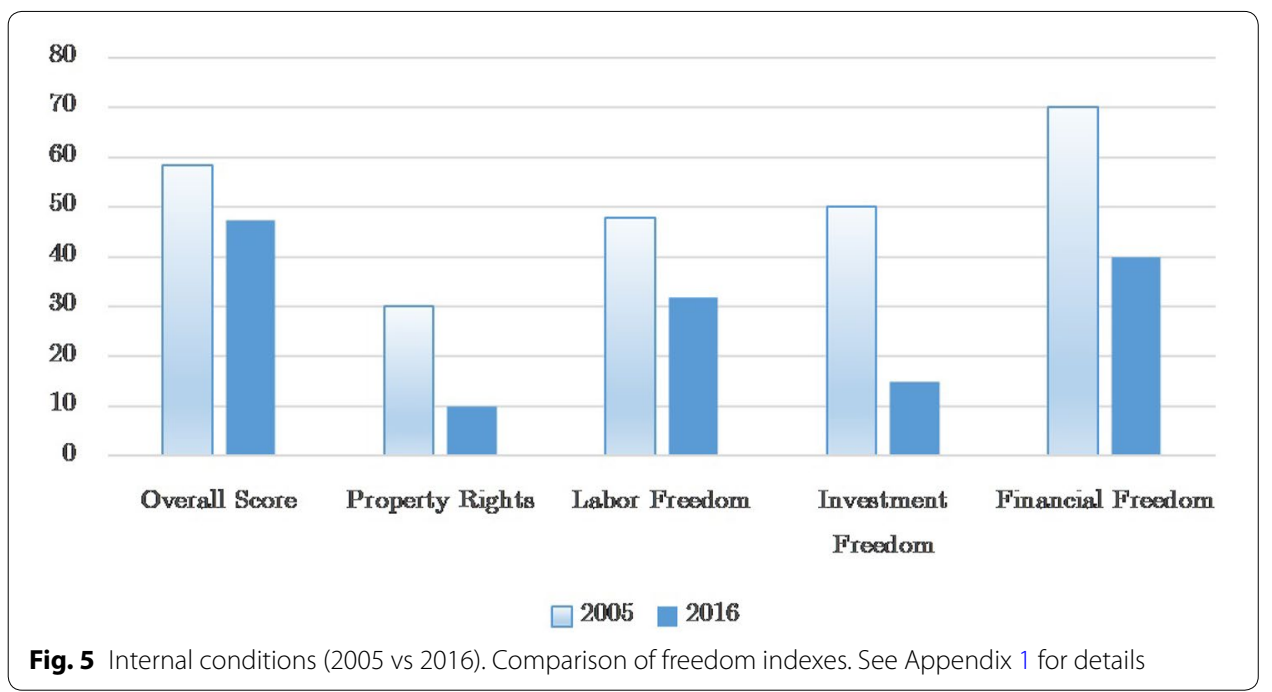

Table 3 Panel data results

\begin{tabular}{ll}
\hline Parameter & Estimate \\
\hline$\delta_{1}$ & $1.1008(0.0285)$ \\
$\delta_{2}$ & $-0.2635(0.0273)$ \\
$\beta$ & - \\
$\gamma$ & $-0.0028(0.0008)$ \\
$\phi$ & $0.0006(0.0002)$ \\
$\theta$ & $0.0018(0.0004)$ \\
Countries & 175 \\
Years & $11(2005-2016)$ \\
Observations & 1815 \\
$R^{2}$ & 0.9989 \\
SER & 0.0414 \\
DW & 1.7894 \\
WE $(x)$ & {$[0.059]$} \\
WE $(p)$ & {$[0.252]$} \\
\hline Und & \\
\hline
\end{tabular}

Unbalanced panel with country fixed effects. External factor proxied by (the log of) terms of trade. Labor Market Freedom Index used as the internal factor

Countries, number of countries included; years, years included (2005-2016); observations, total number of observations included; $R^{2}$, adjusted $R$ squared; SER, standard error of the regression; DW, Durbin Watson; WE $(x)$, Hausman test of weak exogeneity for the external factor (Bolivia); WE ( $p$ ), Hausman test of weak exogeneity for the internal factor (Bolivia). Standard errors in parenthesis. $P$-values in brackets

with terms of trade, and satisfies the specification tests. Thus, this is the variable chosen as proxy of $p .^{22}$

Table 3 reports the results of estimating a panel data models with fixed country effects. ${ }^{23}$ It also reports weak exogeneity tests for the external and internal factors. In both cases, the null hypothesis of no correlation between the residuals for Bolivia of the

\footnotetext{
${ }^{22}$ The results are robust to the choice of proxy for internal conditions. A previous version of the paper also considered the share of government expenditures over GDP as a proxy for $p$, with similar results.

23 As should be expected, Hausman specification tests reject the null of random effects in favor of fixed effects. A LRT rejects the null of redundant fixed effects. Finally, cross-dependence tests reject the null hypothesis of no correlation among the residuals of each country (Pesaran 2015).
} 
Table 4 Scenarios considered

\begin{tabular}{lll}
\hline & Good skills (GS) & Bad skills (BS) \\
\hline Good luck (GL) & A & B \\
Bad luck (BL) & $C$ & D
\end{tabular}

GL (BS) considers the observed sequence of terms of trade (Labor Freedom Index). BL (GS) considers that the terms of trade (Labor Freedom Index) for the period of the treatment remain as in 2005

panel data models (conditional density) and the residuals of the marginal specification for each factor, estimated solely for Bolivia using AR(1) models, is not rejected. ${ }^{24}$ Thus, inference, conditional on contemporary internal and external factors, is valid and no further estimation issues are considered to be problematic.

To conduct the counterfactual exercise, it is required for the variables subject to intervention to be super exogenous, in the sense of Hendry (1995), to the parameters of interest. To test this, we must find evidence of structural instability in the marginal densities of the internal and external factors, while the conditional density remained stable. The $\mathrm{AR}(1)$ models used for the weak exogeneity tests are unstable, as judged by CUSUM tests for Bolivia, while the panel model is stable in the sample considered.

With this background, our counterfactual exercises ask the question: What would have happened with Bolivia if the conditions (internal and/or external) observed prior to the treatment (2005), would have remained unchanged after the treatment?

Table 4 shows four combinations of internal and external factors. If external factors are exogenous and can not be affected by the government, extremely favorable terms of trade as observed during the treatment (after 2005) can be labeled as "good luck" (GL). Thus, "bad luck" (BL) is defined as facing the same level of terms of trade during the treatment (after 2005) of the year 2005. On the other hand, our proxy for internal conditions that are consistent with the policies and statements of the Bolivian government tends to show increasing distortions faced by the private sector. As the panel data results and economic theory tend to predict, these distortions would (generally) be welfare deteriorating and reduce consumption, investment, and formal sector employment. ${ }^{25}$ Thus, we label as "good skills" (GS) to maintaining the level of the Labor Market Freedom Index observed in 2005, and "bad skills" (BS) to the actual index that displays a clear deterioration on this dimension. ${ }^{26}$

As the specification of Table 3 evidences, there is an interaction between terms of trade and labor market freedom, thus making the effects of luck and skills nonlinear. To evaluate the effect of luck (or skills) on GDP per capita, we need to consider the behavior of the skills (or luck). For example, to evaluate the marginal effect of GL, we need to keep

\footnotetext{
${ }^{24}$ Other specifications tests for the residuals of the panel (conditional) and univariate times series models (marginal) indicate that the residuals can be broadly characterized as homoskedastic, normal, and white noise processes.

25 In fact, distortions in the formal labor market have deteriorated so much that, according to Medina and Schneider (2018), Bolivia has the biggest informal sector in the world. For partial equilibrium evidence, see Nogales et al. (2019). For general equilibrium evidence, see Román (2011), Vargas (2009), or Sect. 4 below.

${ }^{26}$ Describing as "good skills" to the economic policies pursued prior to 2006 is, admittedly, a bit of a stretch. Economic policies and political internal conditions have always produced a fragile environment in Bolivia. While corruption and distortions have always been present, these characteristics have increased substantially under the "treatment" . Furthermore, expropriations and reversals of market oriented policies have been a constant feature of the past years, as evidenced by the evolution of all the freedom indexes of the Heritage Foundation.
} 

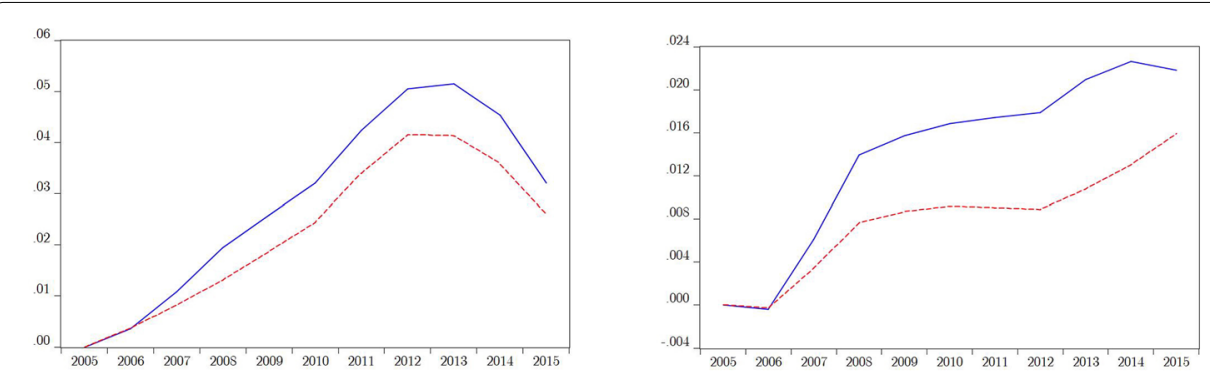

Fig. 6 Effects of skills versus luck (fraction of GDP per capita). Left panel: Solid line depicts the effect of GL conditional on GS (A-C) and dashed line depicts the effect of GL conditional on BS (B-D). Right panel: Solid line depicts the effect of GS conditional on GL (A-B) and dashed line depicts the effect of GS conditional on $\mathrm{BL}(\mathrm{C}-\mathrm{D})$

constant the level of skill. Thus, A-C is the effect of GL, conditional on GS, and B-D is the effect of GL, conditional on BS. Conversely, A-B is the effect of GS, conditional on GL, and C-D is the effect of GS, conditional on BL. If B were an accurate description of Bolivia after the treatment, A would be the counterfactual in which Bolivia would have benefited from the same favorable external conditions, with internal policies that would have enhanced the effect of the commodity prices bonanza.

With the estimates of the specification of Tables 3 and (4), we can compute the expected effect of comparing scenario $k$ with scenario $l$ as:

$$
\begin{aligned}
\Delta^{k-l}= & \sum_{j=1}^{J} \widehat{\delta}_{j}\left(y_{i, t-j}^{k}-y_{i, t-j}^{l}\right)+\widehat{\beta}\left(x_{i, t}^{k}-x_{i, t}^{l}\right) \\
& +\widehat{\gamma}\left(p_{i, t}^{k}-p_{i, t}^{l}\right)+\widehat{\phi}\left(x_{i, t}^{k} p_{i, t}^{k}-x_{i, t}^{l} p_{i, t}^{l}\right),
\end{aligned}
$$

where $k, l=\mathrm{A}, \mathrm{B}, \mathrm{C}, \mathrm{D}$, and $i$ represents Bolivia.

Figure 6 presents the results of computing the differences described in (5). As intuition would prescribe, good luck is "good," unconditionally. However, good skills enhance the effects of a positive external environment. Given the observed path of terms of trade, GDP per capita increased in up to $4 \%$ just due to this effect. On the other hand, maintaining fewer distortions, with the external commodity prices bonanza, would have increased GDP per capita in up to $2 \%$, on average, compared to the observed scenario. Thus, this exercise shows that Bolivia's recent economic bonanza is mostly due to the extremely favorable external conditions it faced, and that, if anything, the internal factors prevented Bolivia from enjoying greater benefits.

\section{DSGE approach}

The previous sections attempt to quantify the effects of Evo Morales's Presidency relying on econometric methods that, through different means, build a counterfactual with which to compare the actual performance of Bolivia.

Although these methods have their merits, they do not provide deep insights regarding the explicit mechanisms that operate. In short, these methods may help to predict, but lack of the economic theory required to understand. 
As mentioned, Lucas (1987) proposed a different approach to evaluate counterfactual scenarios, proposing to use DSGE models as tools for conducting artificial experiments. This approach considers that if there are structural parameters that are invariant to interventions, we can evaluate the effects of interventions by solving the model before the intervention, solving it again with the intervention in place (provided that it is permanent) and compare the long-run (or steady state) effects of the intervention. If the intervention is deemed transitory, a natural tool to tackle the effect of the intervention is to map it to a impulse-response surface. ${ }^{27}$

One weakness of the approaches followed in Sects. 2 and 3 is that the quantitative results are sample dependent. One weakness of the approach of this section is that the results are theory dependent. This, however, should not demean the elegance and boldness of this approach, as it makes transparent the structure used, and the mechanisms through which an intervention operates.

This section uses a deterministic version of the DSGE model developed by Chumacero et al. (2004) to address the issue of the effects of the Free Trade Agreements signed by Chile. ${ }^{28}$ It is general enough, so as to provide a wide variety of mechanisms to analyze, and allows us to operationalize what we mean by luck and skills. Of course, the model is calibrated to replicate some long-run characteristics of Bolivia, and then modified to evaluate the effects of counterfactual scenarios that intend to capture luck and skills.

\subsection{The model}

The model considers a small open economy with firms in three sectors (exportable, importable, and non-tradable), a government, and a representative household that faces an upward-sloping supply schedule for debt.

\subsubsection{The households}

The economy is inhabited by a representative agent, who maximizes the value of lifetime utility as given by: ${ }^{29}$

$$
\sum_{t=0}^{\infty} \beta^{t} u\left(c_{m, t}, c_{n, t}\right)
$$

where $c_{m, t}$ and $c_{n, t}$ represent period $t$ consumption of an importable $(m)$ and a non-tradable good $(n)$. The other good produced in this economy is not consumed at home. We denote this good as the exportable good $(x)$.

The maximization of (6) is done subject to the budget constraint: ${ }^{30}$

$$
\begin{gathered}
\left(1+\tau_{m}\right)\left(1+\tau_{c_{m}}\right) c_{m}+\left(1+\tau_{c_{n}}\right) c_{n} p+\left(1+\tau_{m}\right)\left(1+\tau_{c_{m}}\right) i+(1+\widetilde{r}) b \\
\leq\left(1-\tau_{k}\right)\left(1+\tau_{m}\right)\left(1+\tau_{c_{m}}\right) r k+b_{+1}+F+\pi_{x}+\pi_{m}+\pi_{n} .
\end{gathered}
$$

\footnotetext{
${ }^{27}$ As noted by a referee, a third approach would require to solve the entire transitions subject to (possibly) time-varying policies, and compare the entire time series.

${ }^{28}$ For completeness, the model is presented in its entirety.

29 As noted by a referee, we focus on comparing steady states before and after the treatment. As uncertainty is not required, we consider a deterministic version of the DSGE model of Chumacero et al. (2004).

${ }^{30}$ For brevity, time $t$ subscripts are eliminated.
} 
where $\tau_{m}$ is an import tariff, $\tau_{c_{n}}$ and $\tau_{c_{m}}$ are taxes on the consumption of non-tradables and importables, $p$ is the relative price of the non-tradable good in terms of the importable good (used as numeraire), $b$ is the amount of foreign debt that the private agent contracted from abroad on the previous period, $\widetilde{r}$ is the (net) interest rate paid on that debt, $\tau_{k}$ is a tax on capital income levied by the government, $r$ is the rental rate of capital stock that is given to the firms of the three sectors, $\pi_{x}, \pi_{m}$, and $\pi_{n}$ are the profits of the exportable, importable, and non-tradable sectors, $F$ is a lump sum transfer from the government to households, and $i$ is investment, which satisfies the standard law of motion for capital:

$$
k_{+1}=(1-\delta) k+i,
$$

where $\delta$ is the depreciation rate of the capital stock and $k$ is the capital stock. As $k$ is expressed in units of the importable good, it is also subject to the same taxes of the importable good destined to consumption (tariffs and the value-added tax). ${ }^{31}$

The problem of the representative consumer can be summarized by the value function that satisfies:

$$
V\left(s_{h}\right)=\max _{c_{m}, c_{h}, b_{+1}, k_{+1}}\left\{u\left(c_{m}, c_{n}\right)+\beta\left[V\left(s_{h,+1}\right)\right]\right\},
$$

subject to $(7,8)$, and the perceived laws of motion of the states $s_{h} \cdot{ }^{32}$

The first-order optimality conditions are:

$$
\begin{aligned}
p^{-1} & =\frac{u_{c_{m}}^{\prime}}{u_{c_{n}}^{\prime}} \frac{\left(1+\tau_{c_{n}}\right)}{\left(1+\tau_{m}\right)\left(1+\tau_{c_{m}}\right)} \\
1 & =\beta\left[\frac{u_{c_{m},+1}^{\prime}}{u_{c_{m}}^{\prime}} \frac{\left(1+\tau_{m}\right)\left(1+\tau_{c_{m}}\right)}{\left(1+\tau_{m,+1}\right)\left(1+\tau_{c_{m},+1}\right)}\left(1+\widetilde{r}_{+1}\right)\right] \\
1 & =\beta\left[\frac{u_{c_{m},+1}^{\prime}}{u_{c_{m}}^{\prime}}\left[\left(1-\tau_{k,+1}\right) r_{+1}+1-\delta\right]\right] .
\end{aligned}
$$

The first intratemporal optimality condition states that the relative price between importables and non-tradables (real exchange rate) must equate the ratio of marginal utilities between both goods. The next two (intertemporal) conditions are the standard Euler equations that state that the marginal rate of substitution between consumption today and tomorrow, must equate their relative price, evaluated at the cost of foreign borrowing and the rate of return of capital investment, respectively.

\subsubsection{The firms}

Three sectors with an equal number of representative firms produce the exportable, importable, and non-tradable goods. All sectors require capital as the only explicit production factor. ${ }^{33}$ Next, we state the problems faced by the firms.

\footnotetext{
$\overline{31}$ As pointed out by a referee, this is a simplifying assumption, as investment has tradable and non-tradable components.

32 We define $s_{h}=\left(\tau_{m}, \tau_{c_{m}}, \tau_{c_{n}}, p, \widetilde{r}, \tau_{k}, r, k, b, F, \pi_{x}, \pi_{m}, \pi_{h}\right)$.

${ }^{33}$ This setup is consistent with a model in which labor is sector specific and is static.
} 
The importable good The profits of the representative firm are determined by:

$$
\pi_{m}=\left(1+\tau_{m}\right) f\left(z_{m}, k_{m}\right)-\left(1+\tau_{m}\right)\left(1+\tau_{c_{m}}\right) r k_{m},
$$

where $z_{m}$ is a productive shock and $k_{m}$ is the amount of capital demanded.

The first-order optimality condition is:

$$
f_{k_{m}}^{\prime}\left(z_{m}, k_{m}\right)=\left(1+\tau_{c_{m}}\right) r
$$

which states that the marginal cost of new capital must equate its marginal value.

The output of this sector can be consumed or used as capital in any of the three sector.

The exportable good The profits of firms producing the exportable good are determined by:

$$
\pi_{x}=\left(1-\tau_{x}\right) q f\left(z_{x}, k_{x}\right)-\left(1+\tau_{m}\right)\left(1+\tau_{c_{m}}\right) r k_{x},
$$

where $\tau_{x}$ is an export tax, $q$ is the relative price of exportables in terms of importables, $z_{x}$ is a productive shock, and $k_{x}$ is the amount of (importable) capital demanded by the exportable sector.

The first-order optimality condition is:

$$
\left(1-\tau_{x}\right) q f_{k_{x}}^{\prime}\left(z_{x}, k_{x}\right)=\left(1+\tau_{m}\right)\left(1+\tau_{c_{m}}\right) r,
$$

This equation presents the optimality condition equivalent to (12).

The output of this sector is only consumed abroad.

The non-tradable good The profits of the representative firm are determined by:

$$
\pi_{n}=p f\left(z_{n}, k_{n}\right)-\left(1+\tau_{m}\right)\left(1+\tau_{c_{m}}\right) r k_{n},
$$

where $z_{n}$ is a productive shock and $k_{n}$ is the amount of (importable) capital demanded by the sector.

The first-order optimality condition is:

$$
p f_{k_{n}}^{\prime}\left(z_{n}, k_{n}\right)=\left(1+\tau_{m}\right)\left(1+\tau_{c_{m}}\right) r,
$$

which states the optimality condition of the sector, and has the same interpretation of (14).

The output of this sector is only consumed in the domestic economy.

\subsubsection{The government}

It is assumed that the government has no explicit objective function to maximize, but satisfies the following constraint:

$$
\begin{aligned}
g+F= & \tau_{m}\left(c_{m}+i-f\left(z_{m}, k_{m}\right)\right)+\tau_{c_{m}}\left(1+\tau_{m}\right)\left(c_{m}+i\right) \\
& +\tau_{x} q f\left(z_{x}, k_{x}\right)+\tau_{c_{n}} c_{n} p+\left(1+\tau_{m}\right)\left(1+\tau_{c_{m}}\right) \tau_{k} r k,
\end{aligned}
$$

It is further assumed that a fraction $\varkappa_{t}$ of the total government expenditures is used to consume the non-tradable good produced in the economy. 


\subsubsection{Market-clearing conditions}

Define the productions of the exportable, importable, and non-tradable goods by:

$$
\begin{aligned}
y_{x} & =f\left(z_{x}, k_{x}\right) \\
y_{m} & =f\left(z_{m}, k_{m}\right) \\
y_{n} & =f\left(z_{n}, k_{n}\right) .
\end{aligned}
$$

The market-clearing conditions are:

$$
\begin{aligned}
p y_{n} & =p c_{n}+\varkappa g, \\
-\left(b_{+1}-b\right) & =q y_{x}+y_{m}-c_{m}-(1-\varkappa) g-k_{+1}+(1-\delta) k-\widetilde{r} b,
\end{aligned}
$$

where the first equation describes the equilibrium in the non-tradable good market and the second the equilibrium in the importable good market, which shows that the current account balance must be compensated by the capital account balance.

To avoid having to model the world credit market, and following Bhandari et al. (1990), Turnovsky (1997), and Osang and Turnovsky (2000), we assume that the country faces an upward-sloping supply schedule for debt:

$$
\widetilde{r}=\widetilde{r}(b), \quad \widetilde{r}^{\prime}>0 .
$$

\subsubsection{Competitive equilibrium}

A competitive equilibrium is a set of allocation rules $c_{m}=C_{m}(s), c_{n}=C_{n}(s), k_{+1}=K(s)$, and $b_{+1}=B(s), k_{x,+1}=K_{x}(s), k_{n,+1}=K_{n}(s)$, and $k_{m,+1}=K_{m}(s)$, a set of pricing functions $r=R(s)$, and $p=P(s)$, and the laws of motion of the exogenous state variables $s_{+1}=S(s)$, such that

- Households solve the problem (9), taking as given $s$ and the form of the functions $R(s)$, $P(s)$, and $S(s)$, with the equilibrium solution to this problem satisfying $c_{m}=C_{m}(s)$, $c_{n}=C_{n}(s), k_{+1}=K(s)$, and $b_{+1}=B(s)$.

- Firms of the exportable, importable, and non-tradable sectors solve the problems (11), (13), (15), taking as given $s$ and the form of the functions $R(s), P(s)$, and $S(s)$, with the equilibrium solutions to these problems satisfying $k_{x,+1}=K_{x}(s), k_{n,+1}=K_{n}(s)$, and $k_{m,+1}=K_{m}(s)$.

- The economy-wide resource constraints (19) hold each period, and the factor market clears:

$$
K_{x}(s)+K_{n}(s)+K_{m}(s)=K(s) .
$$

\subsection{Functional forms}

With the generic model specified, next we group functional forms in terms of preferences, production technology, government, and exogenous prices.

\subsubsection{Preferences}

We consider the following functional form:

$$
u\left(c_{m, t}, c_{n, t}\right)=\theta_{m} \ln c_{m, t}+\theta_{n} \ln c_{n, t},
$$

with $\theta_{m}, \theta_{n}>0$ and $\theta_{m}+\theta_{n}=1$. 


\subsubsection{Production technology}

The production functions are assumed to be Cobb-Douglas:

$$
f\left(z_{j, t}, k_{j, t}\right)=e^{z_{j, t}} k_{j, t}^{\alpha_{j}},
$$

where $\alpha_{j}$ is the compensation for capital as a share of output of sector $j$ for $j=x, m, n$.

As we will compare deterministic steady states to evaluate the relative importance of skills and luck, the steady-state values of the productivity shocks $\left(z_{j}\right)$ are calibrated to match the sectorial composition of GDP in Bolivia.

\subsubsection{Fiscal variables}

We calibrate different values for government expenditures $(\bar{g})$ and other fiscal variables (taxes and tariffs), depending on whether or not we activate the treatment, reflecting that distortions increased during the treatment (bad skills). The specific way in which these variables are set is discussed below.

\subsubsection{Exogenous prices}

Next, we describe the functional forms chosen for the laws of motion of two external variables: terms of trade $(q)$ and the borrowing rate $(\widetilde{r})$ discussed in $(20)$.

The steady state of terms of trade $(\bar{q})$ is contingent on whether or not we activate the condition of a favorable terms of trade to assess the effects of "luck" . Further discussion is given below.

Finally, as discussed above, we assume that the country faces an upward-sloping supply schedule for debt and model it as:

$$
\widetilde{r}_{t+1}=\bar{r}+\varphi \frac{b_{t}}{y_{t}},
$$

where $y_{t}$ is total output (GDP), expressed in terms of importables.

\subsection{Calibration and results}

Next, we parameterize the model, distinguishing deep parameters from those that are considered to be affected by the treatment. Table 5 presents the values of the parameters that are assumed to be unchanged by the treatment and Table 6 the values of the parameters before and after the treatment.

\section{Table 5 Deep parameters}

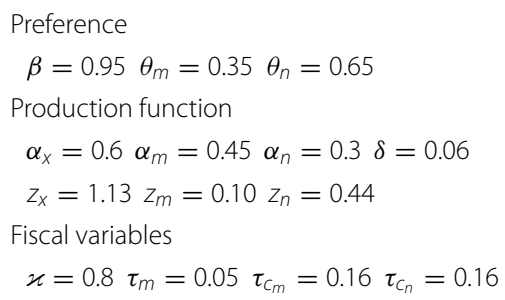


Table 6 Values of the parameters before and after the treatment

\begin{tabular}{lc}
\hline Good & Bad \\
\hline Skills & \\
$\tau_{k}=0.25$ & $\tau_{k}=0.2975$ \\
$\tau_{x}=0.25$ & $\tau_{x}=0.2975$ \\
$\bar{g}=0.95$ & $\bar{g}=1.1305$ \\
Luck & \\
$\bar{q}=0.207$ & $\bar{q}=0.18$ \\
\hline
\end{tabular}

The parameters $\theta_{m}$ and $\theta_{n}$ are chosen so as to reproduce the share of consumption on importables and non-tradables over total consumption in steady state. The subjective discount factor $(\beta)$ was set to make it consistent with a $5 \%$ annual real interest rate.

The output-factor elasticities in each sector $(\alpha)$ were set to match the sectorial shares on GDP, and consider that the exportable sector is more capital intensive than the other sectors. $^{34}$ The depreciation rate was set to $6 \%$, while the constants of the production functions, government expenditures, and terms of trade were set to match the participation of each sector in total GDP. ${ }^{35}$

Table 6 reports how we capture the effects of good luck and good skills. Regarding luck, it is associated with a positive terms of trade shock (increased $q$ ). During the treatment (after 2005), terms of trade were (on average) 50\% higher than the average of the period before (1990-2005), and almost 40\% higher (on average) than in the year before the treatment. As we are comparing steady states, it would be incorrect to assume that this increase is permanent. What we need is to obtain the level of a permanent shock that is equivalent (in present value) to a $50 \%$ temporary increase in terms of trade of 10 years. That is, we need to find:

$$
\lambda_{q}=1.5\left(1-\beta^{9}\right)+\beta^{10} \simeq 1.15
$$

and consider a steady-state level of terms of trade $15 \%$ higher when we evaluate the effect of GL.

It is a bit more difficult to assess what the effects of the treatment were on the increased distortions faced by agents. ${ }^{36}$ Furthermore, reliable figures for the finances of the public sector are not available. ${ }^{37}$ What is clear is that the size of the public sector and the distortions have increased markedly, making private investment more costly, levied heavier taxes on the exportable sector and increased overall government expenditures. The magnitude

\footnotetext{
${ }^{34}$ The long-run shares on GDP for each sector are $11 \$$ for exportables, 31\% for importables, and 58\% for non-tradables.

35 The tax on importables is set relatively low, as tariffs are low and a very dynamic smuggling sector is prevalent. Taxes on consumption of importables and non-tradables are set approximately equivalent to the value-added tax.

36 As discussed in Sect. 3, the indexes that proxy indicators of freedom have deteriorated by between 11 and 35 points. Furthermore, private investment and formal firms have faced expropriations. Finally, a large component of the increased distortions have taken the form of unproductive public investment and corruption. Linares (2018) shows that most of the public enterprises created under Evo Morales run deficits. These enterprises include a cell phone and computer company, a paper company, and textiles, among others. Public investment has also been used to build artificial grass soccer fields (a major hobby of Evo Morales) and a museum on his honor. Public investment changed from 620 million US\$ in 2005 to 5.1 billion dollars in 2016.

37 For example, the IMF, ECLAC, the Bolivian Central Bank, the National Bureau of Statistics, and the Finance Ministry have different figures for the size of the public sector on the economy. This figures range from between $15 \%$ to almost $50 \%$. The last figure is constructed by Kehoe et al. (2019).
} 
of this changes is computed so as the share of government expenditure over GDP after the positive terms of trade shock increases by $2 \%{ }^{38}$ This is equivalent to increasing government expenditures and taxes on capital and the exportable sector of $19 \%{ }^{39}$

As with Sect. 3, here we conduct counterfactual experiments by changing parameters, solving the model with different configurations, and evaluating the effect on the variable of interest (what the model considers to be GDP).

As mentioned, there are several ways in which the exercise could be done. One, in which modifications are considered transitory, is to shock the system with a perturbation and follow the results. In this case, the laws of motion of the states (particularly their persistence) are key. As the model lacks of an analytical solution, numerical methods need to be used to solve for the optimal policies. In case second-order perturbation methods are used (as in Schmitt-Grohé and Uribe 2004), the volatility of the shocks would also be important. The other way to tackle the question is to consider that the counterfactual (or treatment) involves a permanent change in some variables. In that case, we could also evaluate the effects by comparing changes in the optimal policies, or simply evaluating the long-term effects by comparing changes in the (deterministic) steady states. The advantage of this approach is that it solves the fully fledged nonlinear steady state of the system, and does not require approximations of the policy functions. Furthermore, as far as the deterministic steady states are concerned, persistence and volatility are irrelevant. This is the approach we follow.

Concretely, we consider the same scenarios presented in Table 4. As the model is extremely nonlinear, it will be the case that changes in luck (skills) would have different effects on the economy, depending on the skills (luck) scenario that is considered.

As changes in terms of trade and/or distortions will lead to changes in allocations and relative prices, differences in GDP in each scenario are not directly comparable to the ones obtained in the previous sections. This is so, because in them, comparisons were made in dollars of a base year, while here, they are made in GDP expressed in terms of importables. One way to make the figures comparable is to compute GDP in prices of a baseline scenario. A natural baseline scenario would be Bolivia prior to the treatment, which in our case, corresponds to scenario $C$.

Figure 7 presents the results of comparing the changes in the steady-state GDPs of different scenarios, computed in terms of importables, and also in prices of scenario C. As previously, good luck is "good" unconditionally, and good skills enhance the effects of a positive external environment. These results suggest that the long-term effects of a substantial increase in terms of trade would have led to increases in GDP of between 8.9 and 9.9\% when measured at the new relative prices. When measured at constant (scenario C) prices, the increments in GDP due to favorable terms of trade are between 3.7 and $4.1 \%$. Figures are in line with our results of Sect. 3. On the other hand, good skills (less distortions) would amount to increases in GDP of between 6.4 and 7.4\% (depending on the levels of terms of trade), when measured allowing changes of the real exchange rate, and between 5.6 and $6.1 \%$, when measured at prices of scenario C. Thus, this exercise

\footnotetext{
${ }^{38}$ Again, different official sources tell different stories regarding this magnitude. Public consumption and public investment have increased their participation on GDP by, between 3 and 10\%, depending on the source considered. Total tax revenues (as a share of GDP) have increased by 1.7\% (on average) according to the Ministry of Finance.

39 A referee suggested using Mendoza et al. (1994) to calibrate taxes. This task probed to be impossible as there are no reliable statistics of the different sources of tax revenue and tax base that can be used.
} 


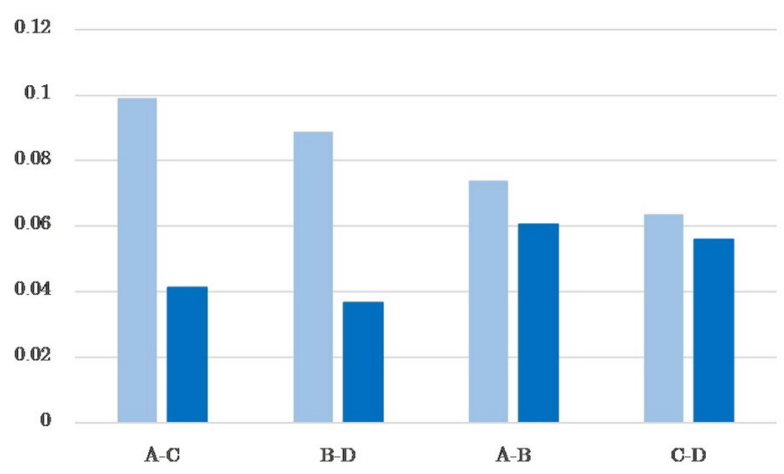

Fig. 7 Effects of skills versus luck with DSGE (fraction of GDP per capita). A-C depicts the effect of GL conditional on GS. B-D depicts the effect of GL conditional on BS. A-B depicts the effect of GS conditional on GL. C-D depicts the effect of GS conditional on BL. The lighter bars evaluate changes in GDP with the relative prices changed due to the scenarios. The darker bars correspond to the changes evaluated at the relative prices of the baseline scenario (C)

provides further support to the hypothesis that Bolivia's recent economic bonanza is mostly due to the extremely favorable external conditions it faced, and that, the internal factors were very costly.

\section{Concluding remarks}

This paper intends to evaluate the relative importance of internal and external conditions on the economic bonanza Bolivia experienced.

As the external conditions were extremely favorable, with increases (of the terms of trade) of, on average, more than $50 \%$ since 2006 with respect to 2005 , or, for that matter, any other period in the past, it is tempting to conclude that this is the main culprit of the bonanza. Nevertheless, Evo Morales's government has not remained still and has also conducted major policy changes. Acolytes of the regime conclude that, it is mainly the policies that should be credited for the boom. Settling this dispute requires more than charts and graphs. As Evo Morales emerged as president of Bolivia in, roughly, the same period of favorable external conditions, it is not trivial to identify the causal effect of each.

This paper provides three complementary approaches to evaluate the relative importance of luck (favorable external conditions) that can not be attributed to the government, and skills (internal policies that could have fostered or lessened the effects of the external conditions). These approaches differ on identifying assumptions, the methodological approach, information used, and foundation on economic theory.

The first approach attempts to construct the counterfactual of how would have Bolivia fared since 2006 if Evo Morales (and his policies) would not have been implemented. To construct this counterfactual, a synthetic control (comprised of a weighted average of other countries) is derived. The results indicate that Evo Morales caused, on average, a loss in the level of GDP per capita of around $4.7 \%$ per year, since in office. They also suggest that conditions in other social indicators would not have been affected in his absence.

The second approach uses a panel of countries to evaluate the precise counterfactual of changing one factor (external or internal), and leaving the other constant. This 
approach imposes some restrictions in terms of the degree of homogeneity in responses by the countries, the proxies considered, and the requirement of super exogeneity (in the sense of Hendry). Meeting these conditions, we find an interesting nonlinearity due to the interaction between internal and external conditions. Put simply, good luck is enhanced with fewer distortions. This approach estimates that good luck provided up to $4 \%$ more on GDP per capita, while the increased distortions in the internal conditions lead to a decrease of up to $2 \%$ of GDP per capita. Thus, not taking into account secular conditions, the bonanza was due to external conditions, with internal conditions harming, more than helping.

The third and final approach uses a DSGE model to evaluate counterfactual scenarios. The model is calibrated so as to replicate the sectorial composition of GDP, and introduces changes in the structure of the model that are intended to accommodate the internal and external conditions observed prior to the treatment (Evo Morales), and change them to compute how the agents would react to them. This approach has the main benefit of providing an optimizing and internally consistent model that has to make explicit the interventions. It also helps to provide economic insights on the mechanisms at play. The results of this approach are qualitatively consistent with the previous findings. With GDP calculated at constant relative prices of the period prior to the treatment, the commodity prices boom may have caused increases of up to 4.1\% (apart from secular trends), while increased internal distortions might have caused around a 6.1\% drop in GDP.

Concluding, all the exercises conducted lead to similar conclusions. Bolivia's recent bonanza is primarily due to incredibly favorable external conditions. If anything, the boom was not fully capitalized due to the increased distortions in the internal economic policies.

Thus, paraphrasing Sir Ronald Ross, the Government's "favorite scam is pretending that luck is skill." ${ }^{40}$

\section{Abbreviations}

BL: bad luck; BS: bad skills; CUSUM: cumulative sum (test); DSGE: dynamic stochastic general equilibrium model; GDP: Gross Domestic Product; GL: good luck; GS: good skills; PPP: purchasing power parity; RMSPE: Root mean squared percentage error.

\section{Acknowledgements}

I thank Boris Branisa, Luis Castro, Rodrigo Fuentes, Daniel Hernaiz, Carlos Gustavo Machicado, Pablo Mendieta, Alejandro Mercado, Oscar Molina, Ricardo Nogales, Antonio Saravia, Rodrigo Villareal, the participants of the 8th Bolivian Conference on Development Economics, the 2018 SECHI Conference, seminars at the Academia Boliviana de Ciencias Económicas, Universidad Católica Boliviana and Universidad Privada Boliviana, and two anonymous referees for helpful comments and suggestions. I also thank Guillermo Gómez, Alejandra Goytia, Esteban Michel, Solange Sardán, Luis Serrudo, and Alejandro Terán, for their valuable research assistance.

\section{Author' contributions}

The author is solely responsible for the article. The author read and approved the final manuscript.

Funding

None.

Availability of data and materials

See Appendix 1 .

Competing interests

The author declares no competing interests.

\footnotetext{
${ }^{40}$ Sir Ronald Ross was a British medical doctor who received the Nobel Prize for Physiology or Medicine in 1902 Humorously, his quote referred to Wall Street. Fittingly, Sir Ross was a pioneer in the systematic analysis of control and treatment groups.
} 
Table 7 Information used in Sect. 2 and Appendix 2

\begin{tabular}{ll}
\hline Variable (source) & Unit \\
\hline Access to electricity (WDI) & \% of population \\
Dropout rate (ES) & Primary school dropout rate (\%) \\
Energy use (WDI) & Kg of oil equivalent per capita \\
GDP per capita (WDI) & Constant 2010 US\$ \\
GDP per capita, PPP (WDI) & PPP (constant 2011 international US\$) \\
Gini (WDI) & Index \\
Gross capital formation (WDI) & \% of GDP \\
Health expenditure (WDI) & \% of GDP \\
Human capital (PWT) & Index \\
Improved water source (WDI) & $\%$ of population with access \\
Infant mortality rate (WDI) & Per 1,000 live births \\
Inflation (WDI) & Annual CPI inflation (\%) \\
Life expectancy (WDI) & Life expectancy at birth (years) \\
Net barter terms of trade (WDI) & X/M unit value indexes relative to 2000 \\
Openness (WDI) & Exports + Imports as \% of GDP \\
Prevalence of anemia (WDI) & \% of children under 5 \\
Share of gov. expenditures (WDI) & \% of GDP \\
TFP (PWT) & Productivity compared with USA =1 \\
\hline
\end{tabular}

WDI, World Development Indicators (The World Bank, 2016); PWT, Penn World Table v9.0 (Feenstra et al. 2015); ES, Education Statistics (The World Bank, 2016)

\section{Appendix 1: The data}

Table 7 lists the series used for the synthetic control approach detailed in Sect. 2. The results of which are reported in Sect. 2 (for GDP per capita) and Appendix 2 (for the Gini coefficient, primary school dropout rate, infant mortality, and life expectancy).

Table 8 lists the series used for the panel data exercise of Sect. 3.

Table 9 lists the series used for the DSGE exercise of Sect. 4.

\section{Appendix 2: Synthetic control: other results}

This Appendix presents the results of applying the synthetic control procedure to assess the effects of the treatment (Evo Morales's Presidency) in four social variables, namely the Gini coefficient, the school dropout rate, infant mortality rate, and life expectancy, as presented in Appendix 1. ${ }^{41}$

As in the case of GDP per capita discussed in Sect. 2, we first find the optimal weights that define the synthetic control. Although the pre-treatment characteristics are always the same (see Table 2), the optimal weights will change depending on the variable of interest $(Z)$. That is, the synthetic control that is used to evaluate the effect of the treatment on, for example, the Gini coefficient will not be the same to one used for other variable.

Table 10 shows which countries are used to form the synthetic control for each variable, while Table 11 presents the list of pre-treatment characteristics that we seek to

${ }^{41}$ We do so because one of the main contentions of the Bolivian government is that there were significant improvements on social conditions that would not have occurred otherwise. 
Table 8 Information used in Sect. 3

\begin{tabular}{ll}
\hline Variable (source) & Unit \\
\hline External debt stock (WDI) & \% of GNI \\
Financial Freedom (HER) & Index \\
GDP per capita, PPP (WDI) & PPP (constant 2011 international US\$) \\
Inflation (WDI) & Annual CPI inflation (\%) \\
Investment freedom (HER) & Index \\
Labor freedom (HER) & Index \\
Net barter terms of trade (WDI) & X/M unit value indexes relative to 2000 \\
Overall freedom (HER) & Index \\
Property rights (HER) & Index \\
Share of gov. expenditures (WDI) & $\%$ of GDP \\
Tax revenue (WDI) & $\%$ of GDP \\
Taxes on international trade (WDI) & \% of revenue \\
\hline
\end{tabular}

WDI, World Development Indicators (The World Bank, 2016); PWT, Penn World Table v9.0 (Feenstra et al. 2015); HER, The Heritage Foundation (2017). All the Heritage Foundations indexes range from 0 (not free) to 100 (free)

Table 9 Information used in Sect. 4

\begin{tabular}{ll}
\hline Variable (source) & Unit \\
\hline GDP (ECLAC) & Constant prices of 1990 \\
Sectoral decomposition of GDP (ECLAC) & Constant prices of 1990 \\
Private consumption (ECLAC) & Constant prices of 1990 \\
Government consumption (ECLAC) & Constant prices of 1990 \\
Exports (ECLAC) & Constant prices of 1990 \\
Imports (ECLAC) & Constant prices of 1990 \\
Investment (RES) & Constant prices of 1990 \\
Population (UN) & Population \\
\hline
\end{tabular}

ECLAC, the Economic Commission for Latin America and the Caribbean (2016); UN, the United Nations Statistics Division (2016); RES, that the series was obtained by residue for the national accounts identity $(I=Y-C-G-X+M)$

match, the values obtained for synthetic Bolivia, and the simple average of the countries considered in each exercise. The number of countries that have information for the Gini coefficient and the dropout rate for the same years that Bolivia has, is reduced. More information is available on infant mortality rate and life expectancy.

Although the synthetic controls do a better job than the simple average of countries, the RMSPE of the synthetic controls used for the Gini coefficient and the dropout rate are substantially higher than the ones for the other two variables, which are in line with the RMSPE of the synthetic Bolivia used in Sect. 2. This means that at least the results for the Gini coefficient and the dropout rate should be viewed with caution.

Figure 8 presents the placebo tests for all the variables. From them, we gather that the treatment (Evo Morales) had no discernible effect on any of the variables considered. In particular, the behavior of the difference between actual Bolivia and synthetic Bolivia pre- and post-treatment is noisy for the case of the Gini coefficient and the dropout rate. Even when there is a slight decline in the infant mortality rate and increase in life expectancy, the synthetic controls do no match well the behavior of these variables prior to the treatment. 
Table 10 Optimal weights for synthetic control: other variables

\begin{tabular}{|c|c|c|c|c|}
\hline Country & Gini & Dropout rate & Infant mortality & Life expectancy \\
\hline Armenia & & & 0.1912 & 0.1471 \\
\hline Brazil & & & 0.2136 & 0.2044 \\
\hline Cote d'Ivoire & & & 0.1798 & 0.1743 \\
\hline Kazakhstan & & 0.2714 & & \\
\hline Kyrgyz Rep. & & & 0.0281 & \\
\hline Morocco & & 0.7286 & & \\
\hline Niger & & & 0.1976 & 0.0889 \\
\hline Nigeria & & & 0.0422 & \\
\hline Panama & 0.1554 & & & \\
\hline Peru & 0.8446 & & 0.1469 & 0.1490 \\
\hline Philippines & & & & 0.0541 \\
\hline Tanzania & & & & 0.1791 \\
\hline \multicolumn{5}{|l|}{ Togo } \\
\hline \multicolumn{5}{|l|}{ UK } \\
\hline Zimbabwe & & & 0.0004 & 0.0030 \\
\hline
\end{tabular}

Table 11 Pre-treatment characteristics

\begin{tabular}{llllllllll}
\hline & Real & Syn [A] & Ave [A] & Syn [B] & Ave [B] & Syn [C] & Ave [C] & Syn [D] & Ave [D] \\
\hline Access to electricity & 65.49 & 71.27 & 89.93 & 71.76 & 96.59 & 62.96 & 82.50 & 57.91 & 82.50 \\
Energy use & 494.83 & 502.18 & 1141.81 & 1159.98 & 2983.42 & 599.40 & 2535.12 & 583.74 & 2535.12 \\
Investment rate & 16.03 & 21.56 & 20.32 & 26.34 & 24.72 & 16.27 & 22.91 & 17.96 & 22.91 \\
Health expenditures & 5.32 & 5.12 & 6.82 & 4.32 & 5.90 & 5.94 & 6.15 & 5.37 & 6.15 \\
Human capital & 2.40 & 2.50 & 2.65 & 1.88 & 2.84 & 1.97 & 2.47 & 1.95 & 2.47 \\
Improved water & 76.05 & 79.91 & 88.50 & 81.55 & 94.51 & 75.19 & 87.54 & 75.89 & 87.54 \\
Inflation & 5.39 & 1.86 & 4.27 & 2.77 & 3.61 & 5.08 & 8.25 & 5.28 & 8.25 \\
Net barter TT & 98.26 & 111.28 & 82.55 & 80.54 & 47.60 & 95.25 & 69.44 & 97.89 & 69.44 \\
Openness & 50.27 & 49.63 & 62.38 & 64.40 & 91.27 & 51.59 & 79.26 & 51.25 & 79.26 \\
Prevalence anemia & 54.27 & 49.28 & 34.49 & 40.63 & 32.43 & 54.72 & 34.28 & 54.55 & 34.28 \\
Share of G & 14.28 & 10.77 & 14.38 & 15.45 & 17.20 & 14.29 & 15.76 & 14.25 & 15.76 \\
TFP & 0.37 & 0.51 & 0.57 & 0.62 & 0.65 & 0.38 & 0.67 & 0.38 & 0.67 \\
Countries & 1 & 2 & 6 & 2 & 12 & 8 & 93 & 8 & 93 \\
RMSPE & 0 & 0.26 & 0.47 & 0.51 & 1.52 & 0.09 & 1.25 & 0.09 & 1.25 \\
\hline
\end{tabular}

[A] Gini. [B] Dropout rate. [C] Infant mortality rate. [D] Life expectancy. All variables are averaged for the period described in Table 2. Real is the average for Bolivia $\left(X_{1}\right)$. Syn is the value for synthetic Bolivia $\left(\widehat{X}_{1}\right)$. Ave is the simple average for all the countries considered to build the synthetic control. Countries denote the number of countries considered. RMSPE denotes the root mean squared percentage error when compared to Bolivia. Further data description is in Appendix 1

In summary, there is no robust evidence to indicate that there were statistically significant improvements on the social indicators considered, due to the Evo Morales Presidency, when compared to the synthetic controls. 

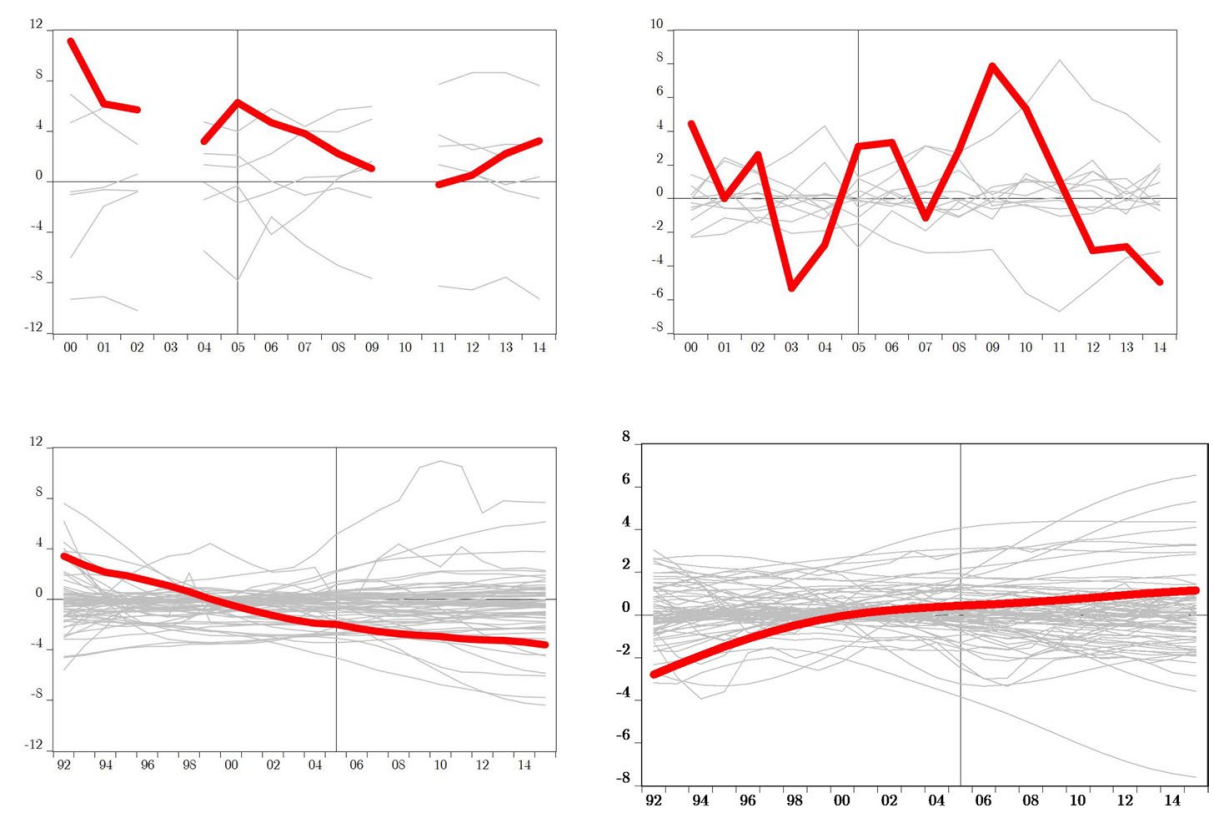

Fig. 8 Placebo tests. The bold lines represent the difference between the observed variable in Bolivia and the synthetic control. The gray lines represent placebo test deviations for the other countries in the data set. The graphs exclude countries with pre-treatment RMSE 2.2 times higher than Bolivia. The vertical line corresponds to the year prior to the treatment (2005). Clockwise, the first panel presents the results for the Gini coefficient, the second for the dropout rate, the third for the infant mortality rate, and the fourth for life expectancy

Received: 21 December 2018 Accepted: 16 July 2019

Published online: 29 July 2019

\section{References}

Abadie A, Diamond A, Hainmueller J (2010) Synthetic control methods for comparative case studies: estimating the effect of California's tobacco control program. J Am Stat Assoc 105(490):493-505

Abadie A, Gardeazabal J (2003) The economic costs of conflict: a case study of the Basque country. Am Econ Rev 93(1):113-32

Angrist J, Pischke J (2009) Mostly harmless econometrics. Princeton University Press, Princeton

Arce L (2016) El Modelo Económico. Social, Comunitario, Productivo Boliviano, Ministerio de Economía y Finanzas Públicas

Bhandari J, Haque N, Turnovsky S (1990) Growth, external debt, and sovereign risk in a small open economy. IMF Staff Papers 37:388-417

Chang R, Kaltani L, Loayza N (2009) Openness can be good for growth: the role of policy complementarities. J Dev Econ 90(1):33-49

Chumacero R, Fuentes R (2006) Economic growth in Latin America: structural breaks or fundamentals? Estudios de Economía 33(2):141-54

Chumacero R, Fuentes R, Schmidt-Hebbel K (2004) Free trade agreements: how big is the deal?, DTBC 264, Central Bank of Chile

Easterly W, Kremer M, Pritchett L, Summers L (1993) Good policy or good luck? Country growth performance and temporary shocks. J Monet Econ 32(3):459-83

Feenstra R, Inklaar R, Timmer M (2015) The next generation of Penn world table. Am Econ Rev 105(10):3150-82

Grier K, Maynard N (2016) The economic consequences of Hugo Chavez: a synthetic control analysis. J Econ Behav Organ 125(1):1-21

Hendry D (1995) Dynamic econometrics. Oxford University Press, Oxford

Imbens G, Rubin D (2015) Causal inference for statistics, social, and biomedical sciences. Cambridge University Press, Cambridge

Kehoe T, Machicado C, Peres J (2019) The Monetary and Fiscal History of Bolivia, 1960-2017, Working Paper 25523, National Bureau of Economic Research

Lee M (2016) Matching, regression discontinuity, difference in differences, and beyond. Oxford University Press, Oxford Linares J (2018) "Má s Ruido que Nueces, Análisis de los Emprendimientos Empresariales del Proceso de Cambio," Grupo Sobre Política Fiscal y Desarrollo, 26, CEDLA

Lucas R (1987) Models of business cycles. Blackwell, Oxford 
Medina L, Schneider F (2018) Shadow economies around the world: what did we learn over the last 20 years?, IMF Working Paper, WP/18/17

Mendoza E, Razin A, Tesar L (1994) Effective tax rates in macroeconomics. cross-country estimates of tax rates on factor incomes and consumption. J Monet Econ 34:297-323

Morales I (2014) editor, ¿Dónde Está la Plata? Cuantificación de los Ingresos Extraordinarios que Percibió Bolivia de 2006 a 2013, Fundaci ón Milenio

Nogales R, Córdova P, Urquidi M, Rejas B (2019) On the relationship between labor market policies and outcomes in Bolivia: a search and matching approach. Estudios de Economía 46(1):61-87

Osang T, Turnovsky S (2000) Differential tariffs, growth, and welfare in a small open economy. J Dev Econ 62:315-42

Pan W, Bai H (2015) Propensity score analysis: fundamentals and developments. The Guilford Press, New York

Pesaran H (2015) Time series analysis and panel data econometrics. Oxford University Press, Oxford

Román S (2011) “Costos Laborales, Economía Informal y Reformas a la Legislación Laboral en Bolivia," Master Of Science Thesis, Universidad de Chile

Schmitt-Grohé S, Uribe M (2004) Solving dynamic general equilibrium models using a second-order approximation to the policy function. J Econ Dyn Control 28:755-75

Turnovsky S (1997) Equilibrium growth in a small economy facing an imperfect world capital market. Revi Dev Econ $1: 1-22$

Vargas J (2009) Bienestar y Ciclos Económicos en una Economía con Evasión y Sector Informal, Ph.D. Thesis, Universidad de Chile

\section{Publisher's Note}

Springer Nature remains neutral with regard to jurisdictional claims in published maps and institutional affiliations.

\section{Submit your manuscript to a SpringerOpen ${ }^{\circ}$ journal and benefit from:}

- Convenient online submission

Rigorous peer review

- Open access: articles freely available online

- High visibility within the field

- Retaining the copyright to your article

Submit your next manuscript at $\gg$ springeropen.com 